\title{
DO MITO ORIGINAL AO MITO IDEOLÓGICO: ALGUNS PERCURSOS
}

Raul FI.KER*

\begin{abstract}
RESUMO: Este artigo é parte de uma Dissertação de Mestrado - "Mito e Paródia: sua estrutura e função no texto literário". - defendida em novembro de 1983 no Instituto de Estudos da Linguagem/Unicamp. A passagem aqui reproduzida pertence ao capítulo que trata da conceituaçào do mito. Ela procura apreender alguns de seus aspectos básicos dinamicamente, na transição de sua forma original, tal como ocorre nas sociedades primitivas e arcaicas, para seu sucedâneo ideológico, no contexto das sociedades históricas.
\end{abstract}

UNITERMOS: Mito; mitologia; consciência mítica; ideologia; sagrado e profano; narrativa.

O conceito de mito, de maneira geral, se refere a um procedimento mental nos quadros da cultura arcaica ou selvagem. Neste sentido, um mito apenas o é até que seja percebido como tal numa avaliação externa, entrando assim em crise. O prisma que vamos abordar agora reflete o sentido oposto: para o pensamento não arcaico ou selvagem, um mito passa a sê-lo depois de identificado como tal, e sua conotação mais direta é a de uma crença rudimentar e enganosa, uma ficção, uma mentira, enfim. É neste contexto que se chama "mitômano" ao mentiroso compulsivo.

No primeiro caso, devido a deslocamentos profundos na superestrutura de determinada cultura, que podem provir de mudanças operadas na infra-estrutura e na interação entre ambas dentro de um processo histórico - como é o caso das transformações no mundo grego entre 8 e 4 a.C.(21) - ou por interferência abrupta e radical de elemento externo - da civilização européia nas culturas ditas primitivas, por exemplo - a consciência mítica e o universo sobre ela estruturado entram em crise e são substituidos por outra episteme: os mitos do universo agonizante deixam de ser mitos no primeiro sentido passando a sê-lo no segundo. No outro caso, no contexto desta nova episteme, algum elemento, até então não problematizado é a uma certa altura posto em questão - passa a ser percebido como falso, ou se percebe que algo era tomado como o que não era, ou se lhe denuncia o caráter fetichista e passa a ser um "mito". A palavra é usada neste espectro - com alguma-variação - quando se diz que "a democracia social escandinava é um mito", isto é, uma ficção, ou "Marilyn Monroe foi um mito sexual dos anos 50" e outros clichês jornalísticos do gênero "Pelé, os Beatles ou Stalin são mitos", isto é, desumanizados e revertidos à condição de ídolo ou fetiche como alvo de adoração (ou de ojeriza). Este.prisma diz respeito a esta passagem: quando o mito deixa de (ou começa a) sê-lo, isto é, passa a ser reconhecido ccmo tal? Quais as ca-

* Departamento de Antropologia, Filosofia e Politica - Instituto de Letras, Ciências Sociais e Educação - UNESP 14.800 - Araraquara - SP. 
racterísticas desse mito dessacralizado, ostensivamente fictício - ou, se formos adaptar o modelo de Lévi - Strauss a este nível - desse modelo lógico que já não resolve nem atenua as contradiçōes básicas em relação às quais fôra elaborado e que talvez mesmo as agrave? Como é o mito nesse seu momento, quando a mitologia clássica, já posta em questão e satirizada desde Evemero (ver mais adiante, p. 14), alegorizada e preconizada como artifício de reforço à autoridade constituída (pelos neoplatônicos e estóicos), é explícita e usualmente desprestigiada na era helenística? Ou quando o romance de cavalaria, veículo do mito básico de uma época, sofre sua morte póstuma com o Dom Quixote? Quais são as características do mito de nossa época?

O mito moderno é em geral abordado em termos de analogias superficiais com comportamentos arcaicos a identificar, entre costumes vestigiais já desprovidos de substrato mítico, "bolsões míticos" na "era científica"' (como o próprio mito da ciência, os símbolos nacionais etc.) e de tentativas de substituição dos mitos religiosos $(3,6)$. O que escapa a esta visão é que o mito moderno, num percurso paralelo e alternativo ao que ef etua desde o mito original para se transformar, através de sucessivas crises, em teoria filosófica ou cientifica, se torna ideologia. Neste caso, mais do que transformação, ocorre permanência, havendo mudança apenas no sentido de adaptação ao novo contexto. Esta adaptação, no entanto, se dá a partir de um descolamento básico e não consegue superá-lo - a não ser através de descaracterização radical do mito, e então já se trata como que de outra coisa e não caberia falar de mito. Se no antigo contexto, o mito fornecia referencial para um universo em relaçào ao qual ele próprio era elemento constituinte, no novo, que é constituido a partir de outro quadro mental, ele fornece apenas falsa consciência, se prestando neste sentido - ainda que com pouca eficácia - a instrumento de dominação.

Assim, a tentativa de recuperação da consciência mítica pode significar várias coisas: para o "ex-primitivo" colonizado, o resgate de sua consciência original anulada pelo invasor europeu, e para este, a retomada de uma unidade perdida consigo mesmo e com o mundo. No momento mesmo da mudança, na Grécia, por exemplo, vemos um Píndaro ou um Aristófanes empenhados numa resistência ambígua: engajados na agonia contra o que vêem como decadência. Por outro lado, a defesa do mito pode ser a defesa - engajada ou inocente - da falsa consciência e do papel que esta geralmente representa nos quadros da dominação política. O mito “tecnificado', por exemplo segundo a definição de Kerényi (13, p.153-68) - é utilizado intencionalmente com fins bem determinados, geralmente políticos. E há também o uso, intencional ou não, através das formas nas quais o mito se degrada. Aqui, porém, já não estamos no domínio do mito mas do meramente mítico(2), que se exprime através do clichê e, no nível do texto literário, produz subliteratura. Pois quando o mito se torna clichê, o lugar de todos os lugares se transforma em lugar-comum.

Examinaremos em seguida alguns niveis da passagem do mito original para o mito ideológico.

\section{Do cosmos à fantasmagoria}

Kósmos, a palavra grega para “mundo”, significa também “ordem”. E para além do mundo clássico, nas grandes cosmogonias orientais, nos mitos totêmicos de origem, ou nas narrativas primitivas e arcaicas sobre o ancestral sagrado que organiza o caos primordial, os dois significados coalescem. O mito, enquanto cosmogonia, é basicamente instaurador, constitutivo de uma ordem universal, de um cosmos. Esta propriedade cosmificante tem alcance mais geral que as demais caracteristicas do mito e abran- 
ge, em maior ou menor grau, algumas delas. As características de unicidade e de conciliar contradições, por exemplo, como será visto, cabem quase inteiramente no domínio do cosmificante, categorias constitutivas, ordenadoras, que são.

Que o mito instaura um universo pode ser visto nas várias cosmogonias, descrições da criação por um demiurgo, deus ou ancestral mítico, do mundo físico e de seus habitantes, às vezes em seguida e no processo mesmo de um combate com forças que representam o caos disforme e indeterminado. Estas descrições se fazem geralmente seguir de listas genealógicas como as que se encontram na Teogonia de Hesíodo, referente aos deuses olimpicos, ou no Gênesis, no relato do Javista referente aos descendentes de Adão. O Enuma Elish (Poema da Criação) babilônico exemplifica notavelmente o modelo cosmogônico caos x cosmos. É uma narrativa que se refere ao combate entre o deus Marduk e Tiamat, o monstro que representa o caos. Vencedor, Marduk cria o cosmos com o corpo dilacerado de Tiamat e o homem com o sangue do demônio Kingu, aliado de Tiamat (7, p. 67-9; 4, p. 74-85; 10, p. 676-7). Tais enf rentamentos entre potências cósmicas e caóticas, estas geralmente representadas por monstros, dragões e serpentes, ocorrem também na Bíblia, nos combates que Jeová move contra Raab ( Jó26 12-13) e Leviatã (Jó-41; Salmo 74:14). Na mitologia grega são inúmeros os enfrentamentos entre as potências olímpicas e os titãs e entidades ctônicas. No Ragnarök ou Götterdämmerung há um retorno ao caos através da derrota do panteão teutônico pelas forças do mal.

Este aspecto constitutivo integra tanto as abordagens tradicionais, anteriores ao naturalismo da segunda metade do século passado, como as tendências modernas no estudo do mito, especialmente as simbolistas. Para J. Campbell, nesta vertente, os mitos e ritos constituem eles mesmos um mesocosmos - um cosmos médio, mediador, através do qual o microcosmos do indivíduo é posto em relação com o macrocosmos do todo. Todos os mitos e rituais são gerados da concepção de uma ordem universal da qual eles são agentes estruturantes, funcionando para tornar a ordem humana de acordo com a celestial (5, p. 149-50). Na mesma vertente simbolista, M. Eliade destaca a importância vital que se atribui, no universo mental do mito, ao conhecimento das origens; estas são dotadas de prestígio mágico, especialmente no que diz respeito às curas médicas. E o mito de origem depende do mito cosmogônico, modelo exemplar de toda criação. Neste contexto, ocupam posição central os mitos e ritos de renovação: a renovatio ef etuada pelo ritual do ano novo é uma reiteração da cosmogonia (8, p. 4152). A cada ritual do ano novo há u m recomeço do mundo; ano e mundo são muitas vezes expressos pela mesma palavra, e com o início de um novo ano/mundo advém um tempo “não usado'”. Para Eliade, a progressiva historização dos enredos arcaicos (entre hebreus e cristãos, p.ex.) tem por ef eito tornar o tempo cíclico linear, com os eventos passando a ser irreversiveis. A “ontologia" dá lugar à "história”, com a ênfase recaindo sobre aquilo que aconteceu aos deuses, e não mais sobre aquilo que eles criaram (8, p. 98-100). A idéia da "perfeição do princípio" foi projetada também num futuro temporal, e os mitos do Fim do Mundo colocam em evidência a mobilidade da origem, que passa a estar também num futuro mítico, para onde igualmente se transfere a noção de uma Idade de Ouro (8, p. 52). Os mitos do Fim do Mundo, implicando mais ou menos claramente a recriação de um novo universo, exprimem a mesma idéia arcaica e extremamente difundida da "degradação" progressiva do cosmos, requerendo sua destruição e recriação periódicas $(8$, p. 38$)$.

O elemento constitutivo é evidente também no procedimento geral do que LéviStrauss chama de "pensamento selvagem", isto é, os processos mentais dos povos totêmicos. Estes dispõem de uma lógica tão exigente quanto a do pensamento positivo e não muito diferente desta. Tal diferença "se deve menos à qualidade das operações que 
à natureza das coisas sobre as quais se dirigem essas operações"' (15, p. 265). LéviStrauss compara o procedimento deste pensamento com a atividade do bricoleur, isto é, aquele que trabalha com meios que não pertencem à tecnologia normal e, ao invés de matérias-primas, utiliza pedaços e sobras de matéria já elaborada. “Os ritos e mitos, à maneira do bricolage (que as sociedades industriais não mais toleram senão como passatempo) decompõem e recompõem conjuntos acontecimentais (no plano psíquico, socio-histórico ou técnico) e deles se servem como de outras tantas peças indestrutiveis em vista dos arranjos estruturais que exercem, alternativamente, o papel de fins ou de meios" (16, p. 55). O dispositivo mítico, procedendo neste âmbito, constitui uma ordem coerente a partir do caos de elementos disponiveis, procedam estes ou não de outras ordens, ainda constituídas ou já caotizadas.

Estes processos concorrem para a formação de um horizonte coerente e significativo onde se desenvolvem, em seus respectivos níveis, no interior de um feixe complexo de interações, as atividades humanas e divinas. A realidade, para o homem primitivo ou arcaico, que vive numa ordem de coisas sacralizada, consiste no conjunto de significados derivados, direta ou indiretamente, do mito básico de sua cultura, veiculado através de uma cosmogonia específica. É o gesto divino de instauração do cosmos que estabelece a ordem em torno e em função da qual se desenrolam as relações concretas dos homens entre si ou com a realidade bruta circundante. Como bem o mostra LéviStrauss, esta Weltanschauung comporta uma lógica própria em nada inferior à sua correspondente européia. Por mais que seus elementos surjam como algo exótico, caprichoso e irracional, aos olhos do homem de uma sociedade moderna tecnológica, eles constituem um sistema íntegro funcionando normalmente em termos de adaptação ao meio ambiente, viabilizando sociedades que chegam a ser complexas.

Já nas sociedades modernas, onde são outros os parâmetros que informam o horizonte de questionamento $(22$, p. 111$)$, os mitos não integram o sistema de maneira harmônica, criando uma região de discrepância. Manifestações vestigiais de um procedimento anacrônico, os mitos básicos que caracterizam uma época formam um mundo desvinculado da realidade, criando e preservando valores-fantasmas cuja relação paradigmática com as práticas concretas da sociedade em questão é apenas caricatural. Se no contexto primitivo ou arcaico o mito limpa, delineia com precisão os significados e revela uma sabedoria em conformidade funcional com aquele sistema, no contexto moderno ele embaça os significados e contribui para a elaboração de uma falsa consciência. Ali ele mitifica o real, aqui ele o mistifica.

O mito como ocorre neste contexto, o mito ideológico, instaura uma falsa ordem, um pseudocosmos povoado de fantasmagorias que, ao invés de informar sobre o concreto, torna-o mal-assombrado. Seu aspecto paradigmático deixa uma borda à ambigüidade: não estará o valor por ele veiculado sendo absorvido como um alto ideal a ser alcançado? Como fim e modelo, como se dava com os deuses em Homero? (20, p. 189). Ou tal valor já é escancaradamente convencional, mascarando um conjunto de práticas que para se perpetuarem procuram a justificativa de se colocarem como elementos preservadores do valor em questão, embora este não exista e as tais práticas sejam na verdade suas antípodas?

Os grandes mitos básicos que caracterizam uma época, se chegam a revelar algo dela é a partir do modo como a disfarçam, pois a preferência por uma máscara específica ao invés de outra qualquer pode ser mais reveladora que o próprio rosto descoberto. E neste processo de disfarçar a realidade acaba entrando algo dela, como material para a fantasia. Assim, por exemplo, os valores cavaleirescos, além de trazerem em sua formação elementos do culto de Maria, da tradição da poesia lírica latina e do amor platônico, transpunham muito da ética feudal, no que toca às relações de susera- 
nia, para o discurso amoroso (11, p. 253-99). Estes valores, na relação entre os sexos, tinham tanto a ver com a realidade quanto nas sociedades modernas o têm os valores $\mathrm{c}$ parâmetros cristãos, democráticos e socialistas nos paises que se intitulam como tais. Estes véus mitológicos criam para uma época um universo inexistente, cujas imagens transparentes podem ser atravessadas pelos corpos como eles passam através de $u$ m fantasma. Sua superposição embaça o mundo real das relaçòes concretas entre os homens, cujo panorama, visto do outro lado das projeçòes fantasmagóricas, se torna opaco e carente de significação densa e instantânea (como a que fornece o mito). ()s valores neles produzidos constituem pontos de referência ritualisticos vazios e a intersecção entre o discurso manifesto e seu conteúdo latente ocorre no avesso de cada parte. E nào faltam os grandes motivos do mito original, vestigio a identificar o (deslocado) procedimento geral: se o cavaleiro andante tem entre seu repertório arquetípico a tarefa de matar um dragão (representação do caos nas cosmogonias arcaicas) e salvar a princesa (imagem que nos chega exausta como clichê e motivo de parúdia), já para o homem moderno nas sociedades tecnológicas, entre as imagens mais freqüentes do discurso ideológico que envolve seu conjunto de valores-fantasma, está o de que estes valores devem ser preservados (no mais das vezes contra eles mesmos, em sua versào real) para evitar que o "caos" e a "treva" que ameaçam "nosso mundo" terminem por descosmificá-lo de vez.

\section{Do sagrado ao dogmático}

A cosmificação é inseparável da consagração. A instauração de um cosmos, constituindo uma ordem universal, abre um espaço sagrado no qual impera o necessário. Ordem e necessidade são os elementos de caráter sagrado constituintes do cosmos, em oposição ao caos, que é profano e dominado pela contingência. Quando o deus, demiurgo ou ancestral primordial estabelece o espaço organizado, tal território sagrado garante sentido às coisas. Nenhuma atividade levada a cabo nesta região fícará ao desabrigo do sentido (7, p. 35-6).

Embora a utilidade de uma noção pouco precisa como a de sagrado para o conhecimento do mito possa ser posta em dúvida (17, p.66), a freqüência com que esta característica do mito é empregada para diferenciá-lo - com êxito - de outras narrativas que se lhe assemelham é indicadora de que tal procedimento pode ser proveitoso. M. Eliade, por exemplo, define o mito como o relato de um acontecimento ocorrido no tempo primordial, descrevendo as diversas irrupçōes do sagrado (ou do sobrenatural) no mundo. "É essa irrupção do sagrado que realmente fundamenta o mundo e o converte no que é hoje', (8, p.11). Sendo uma história sagrada, o mito é, portanto, considerado uma “história verdadeira', porque sempre se refere a realidades (8,p.12).

À medida em que a narrativa mitica se desprega de seu caráter sagrado, dá-se simultaneamente que a realidade dos eventos a que se refere é contestada e seu poder sobre os homens - já esvaido - passa a ser objeto de manipulação. Numa fase já mais adiantada deste processo e paralelamente a ele, já não é sequer a narrativa original ou seus elementos que pretendem o status de sagrado e reivindicam autoridade, mas seu sucedâneo meramente mítico e não necessariamente narrativo.

Este processo de dessacralização seguido de manipulação pode ser nitidamente acompanhado em seu percurso diacrônico, a partir, por exemplo, de cerca do século 6 a.C na Grécia. É por esta época, segundo convenção geralmente aceita (19, p.12), que o mito já é objeto de avaliação externa, com Teagenes de Regium, que inaıgur a na tradição pagã a alegorização de Homero, afirmando serem realidades personificadas cada 
um dos personagens homéricos. A interpretação sof ista (século 5 a.C.) dos mitos tradicionais como alegorias a revelarem verdades naturalistas e morais, continua em uso entre os filósofos neoplatônicos e estóicos do período helenístico, que viam nela uma maneira de preservar a autoridade da tradição e as prerrogativas religiosas do Estado. Os filósofos epicuristas, desde os tempo dos pré-socráticos atomistas Leucipo e Demócrito, consideram os mitos como distorções de eventos históricos e naturais introduzidas para reforçar a autoridade de reis e sacerdotes. Cerca de 316 a.C., a expressão clássica a esta corrente de pensamento é dada pelo macedônio Evemero, autor de uma História Sagrada na qual é narrada uma visita do autor a uma ilha imaginária, Pankaea, no Oceano Índico. Lá ele fica sabendo, a partir de uma inscrição no templo de Zeus, que este deus era um cretense de nascimento que viajou para o leste e lá foi aclamado deus antes de retornar para Creta, onde morreu. Evemerismo tornou-se o nome para todas as explicações puramente históricas do mito.

No início da era cristã os argumentos epicuristas e o evemerismo são usados pelos teólogos contra os mitos pagãos, enquanto os filósofos estóicos e neoplatônicos - que sempre concordaram em que os mitos não deviam ser tomados literalmente - combatem a pretensão cristã à revelação divina exclusiva. Teólogos cristãos e hebreus como Filo e S.Agostinho, interpretaram as narrativas do Velho Testamento alegórica e literalmente, dispensando tratamento diverso aos mitos pagãos, que a partir daí começaram a ser vistos no Ocidente como "mitos" no sentido de narrativas fabulosas e indignas de crédito.

Com o advento da Renascença na Europa, nos séculos 15 e 16, renovou-se o interesse pelos mitos gregos e romanos, cuja interpretação como alegorias morais ou representações poéticas e artísticas das emoções e aspirações humanas era tolerada pela Igreja Católica.

Nos séculos 16 e 17, a mitologia assume um caráter moralizante, exemplar: se Júpiter assume a forma de um touro ou Apuleio é transformado em asno, isto pode apenas significar "que um homem que se entrega à luxúria não passa de um animal" (Robert Burton, THE ANATHOMY OF MELANCHOLY, Londres, 1652, iii.2.3.).

O movimento dos teólogos contra os mitos pagãos no início da era cristã é de certo modo invertido pelos iluministas no século 18. Eles procuram equiparar as escrituras hebraico-cristãs aos mitos pagãos como supertições irracionais em sua tentativa de substituir a religião da fé pela religião da razão. Nesta etapa, se inicia com Giovanni Batista Vico a tendência de recuperação do mito que prevalecerá no romantismo. $\mathrm{O}$ método de interpretação de Vico pode ser caracterizado como "evemerismo alegórico", na medida em que procura reduzir os heróis culturais do mito a símbolos de classe da sociedade.

No decorrer deste processo constante de dessacralização do mito, expresso através de sua avaliação externa ou objetivação, de sua alegorização, manipulação e mesmo de sua tentativa de resgate (que existe sobre o reconhecimento desta dessacralização), desenvolve-se, paralelamente, a substituição do próprio sagrado pelo simplesmente dogmático. Este processo paralelo já não está apenas em função do mito propriamente dito, mas também de elementos não originariamente míticos. Assim, se no universo arcaico ou primitivo, ocorre um discurso sacerdotal, às vezes apoiado na técnica restrita ao escriba, que se mantém numa aura secreta e hermética, no contexto moderno, o próprio "mito" da ciência fornece elementos para a modalidade ideológica do discurso "científico" como instrumento de poder análogo àquele. A terminologia "científica”, seu jargão e tiques discursivos, podem ser empregados, e o são amiúde, para fornecer invólucro respeitável ao que carece de fundamento. E este procedimento de conferir autoridade através da consagração por meio de "palavras mágicas" não se restringe ao 
discurso "científico" apenas, mas abrange também o discurso bacharelesco em geral, cuja função básica é reiterar a autoridade do grupo que ocupa o poder. Tal discurso vazio e grandiloqüente, recheado de lugares- comuns pomposos - entre os quais não faltam, inclusive, alusões mitológicas clássicas ornamentais - equivale, em procedimento e em função, à máscara atemorizante do feiticeiro primitivo.

\section{Do extratemporal para fora do tempo certo}

O evento mítico, como foi visto a propósito das cosmogonias, tem por caracteristica ocorrer fora do tempo. Ele é extratemporal, efetuando-se ab origine, in illo tempore. As ocorrências primordiais se dão antes que haja tempo, abrindo o percurso cíclico deste em direção a seu próprio início. "O tempo sagrado”, diz Eliade (7, p. 634), "periodicamente reatualizado nas religiões pré-cristãs (sobretudo nas religiões arcaicas) é um Tempo mítico, quer dizer, um tempo primordial, não identificável no passado histórico, um Tempo original, neste sentido em que brotou “de golpe', que não foi precedido por outro tempo, porque nenhum tempo podia existir antes da aparição da realidade narrada pelo mito'’. Alguns autores, como G.S. Kirk (14, p. 31-41), utilizam esta característica temporal para especificar o mito em relação ao conto folclórico: enquanto o mito se passa no tempo primordial, durante a criação, o "era uma vez.' do conto folclórico já situa a ação dentro do tempo histórico.

Esta extra-temporalidade, integrada a um sistema onde ela se reveza com o tempo cíclico propriamente dito, num contexto dessacralizado e marcado pelo tempo linear e histórico, passa a ser problematizada. Neste contexto, a fixação no extra-temporal já é passível de conotação ideológica, implicando, de certa forma, uma fuga da História. Mas aqui o que importa é menos esta transição e o deslocamento por ela produzido do que o contraste entre a posição temporal do mito original e a do mito ideológico. Esta pode ser exemplificada pela manif estação do mitico que Barthes mostra a propósito da caracterização do romano antigo no cinema americano $(1, \mathrm{p} .27-30)$ : a presença da pequena franja romana - signo da romanidade - em rostos cuja morfologia - em associação fixada pelo próprio cinema - é a do gangster ou xerife, constitui um quadro geral de anacronismos históricos onde tudo se encontra fora de época.

De maneira geral, o mito ideológico - seja no nivel destas inocentes manifestações do meramente mitico, seja através dos grandes rituais de massas nos quais nazistas e fascistas procuravam reviver mitos arcaicos amplamente distorcidos - está inevitavelmente atolado no anacronismo. A simples manifestação das formas próprias ao mito (embora possam estar veiculando elementos não originariamente miticos mas que procuram impor-se à maneira daqueles) num contexto que não mais as comporta, já configura um desencaixe, um equivoco, uma trapalhada. Este seu aspecto Kitsch, seu desacordo com o contexto e seu estatuto aberrante, comportam possibilidades cômicoburlescas relacionadas ao anacronismo histórico como dispositivo paródico.

\section{Da conciliação ao disfarce das contradições}

O mito, como procura mostrar Lévi-Strauss, ao menos para suas manifestações entre povos totemistas, tem por objetivo a resolução de contradições no seio de uma cultura. Lévi-Strauss, a partir de um procedimento que consiste em reduzir os elementos narrativos do mito a mitemas(15,P.242-3) e experimentar sucessivamente diversas. disposições destes, guiando-se pelos principios que servem de base à análise estrutural 
(economia de explicação, unidade de solução, possibilidade de reconstituir o conjunto a partir de um fragmento e de prever os desenvolvimentos ulteriores a partir dos dados atuais), chega, para o mito de Edipo às seguintes conclusões: O mito de Édipo "exprimiria a impossibilidade em que se encontra uma sociedade que professa a crença na auIoctonia do homem(...) de passar, desta teoria, ao reconhecimento do fato de que cada um de nos nasceu realmente da união de um homem e de uma mulher. A dificuldade é insuperável. Mas o mito de Édipo oferece uma espécie de instrumento lógico que permite lançar uma ponte entre o problema inicial - nascemos de um único ou de dois? c o problema derivado, que se pode formular, aproximadamente: o mesmo nasce do mesmo ou de outro? Por este meio, uma correlação se evidıncia: a superestima do parentesco consangüineo está para a subestima deste, como o esforço para escapar à autoctonia está para a impossibilidade de consegui-lo. A experiência pode desmentir a teoria, mas a vida social confirma a cosmologia na medida em que ambas traem a mesma estrutura contraditória. Então, a cosmologia é verdadeira', (15,p.249-50).

No nivel do mito ideológico não há uma tentativa de conciliar as contradições culturais e sociais, mas de disfarçá-las, varrendo-as para baixo do tapete da falsa consciência. O disfarce pode consistir de uma total camuflagem pelo mito ideológico - como vimos no primeiro elemento deste eixo quanto à pseudo-cosmificação, constituindo um cosmos ilusório a embaçar a visão do universo real interpondo-se entre ele e o observador - , ou pode se dar como pseudo-conciliação. No primeiro caso sequer se reconhecem contradições a serem conciliadas, enquanto que no segundo, onde elas chegam a constar, a conciliação ocorre como uma formalidade, no nivel das aparências. Exemplo desta modalidade é a cena final de “Metropolis"' (1926), filme expressionista de Fritz Lang no qual, após uma prolongada e esquemática exacerbação das contradições entre o capital e o trabalho, estes são simbolicamente (e de forma voluntariamente caricatural, ao que tudo indica) conciliados no caloroso aperto de mãos entre os representantes das partes em conflito.

\section{Da unicidade à desagregação}

Em qualquer concepção da divindade, ela abrange simultaneamente todos os atributos, o que faz da zona de transcendência uma região de unidade. A consciência mística instaura um sentido de união do homem consigo mesmo e com o mundo. Ele é parte de um todo orgânico e significativo. Técnicas místicas hindus - a Yoga e o Tantrismo - buscam a integração de princípios opostos, do tipo dos representados pelo sol e pela lua, como condição prévia para a integração do homem, para além da oposição entre as coisas, no cosmos, unidade primordial. Mitos de reintegração são encontrados por toda parte na história das religiões, numa infinidade de variações (9, p. 146-7, 179, 185). Esta necessidade de abolir dualismos e existências fragmentárias se encontra também no culto do mito pelo Romantismo e se expressa através de um panteísmo de um monismo que identifica Deus e o mundo, corpo e espírito, sujeito e objeto (24, p. 128198).

Quanto ao mito ideológico, que ele atua num contexto de desagregação, decorre do que foi visto até aqui. Ancorado em singularidades, constituído a partir de um ponto de vista parcial e faccioso, na dispersividade do meramente mítico, o mito ideológico é essencialmente fragmentário, truncando as totalidades e oferecendo uma caricatura da organicidade da consciência mítica com o traçado de seu universo ilusório. Constituindo um pseudo cosmos fantasmagórico, ele separa o homem de seu mundo real; petrificando-o no dogmatismo, ele separa o homem de si mesmo, cindindo-o; separa-o de sua época e aliena-o de suas relações concretas; além de cortar seu acesso às próprias contradições, dilacerando-lhe a consciência. 


\section{Da narrativa e da sabedoria ao mítico desarticulado e ao lugar-comum}

O mito ocorre basicamente como narrativa, e é esta sua forma literária. E preciso, no entanto, guardar alguma reserva quanto a esta nomenclatura, pois o mito se dá originalmente a partir da narrativa oral, não dispondo em si mesmo de "forma literária'. Esta lhe é dada a posteriori, ao ser escrito ou anotado, com finalidades sacerdotais, por exemplo - no interior ainda do universo mítico mas já subordinado a uma sintaxe diversa da do enunciado oral, ou já fora de seu ambiente original, como tema literário ou espécimen coletado pelo etnólogo, arqueólogo ou algum outro habitante do logos.

Os mitos do dilúvio universal, por exemplo, ainda que nas mais arcaicas versòes, assim como a épica de Gilgamés ou o Livro dos Mortos egípcio e o Popol Vuhl maia (estes últimos já com implicações sacerdotais) pelo simples fato de serem escritos já trazem elementos de elaboração literária. Além do que, nunca é demais insistir no ponio de que não existe algo como "o mito em si"': trata-se, obviamente, de uma abstração à qual se chega e não de uma realidade da qual se parte. E, finalmente, em relação à própria etapa oral, devem ser lembrados os fatores de elavoração presentes na técnica do contador de histórias primitivo, não-letrado.

É o caráter narrativo, oral ou escrito, que permite a especificação do mito em sua forma literária, seu “estilo" característico. E neste sentido não há melhor pista para esta especificidade do que a origem mesma do termo: a palavra grega $\mu \nu \theta o s$, além de designar uma narrativa concernente à genealogia dos deuses, se refere também a uma narrativa qualquer. Em seu emprego moderno - a despeito da permanência do significado mais geral na vigência da poética aristotélica - restou ao termo apenas o primciro significado, mas é ao segundo que temos de recorrer para capturar o elemento narr ativo a que se resume o mito enquanto modalidade de discurso. Este "estilo evèntico", caracterítisco da manifestação mítica, é tradicionalmente salientado por exegetas como Nietzche, Jolles e Lévi-Strauss (23, p. 28).

Tal característica se delineia originariamente na Grécia de entre os séculos 8 e 4 a.c. É nesse período, de mudanças fundamentais em todas as esferas do universo mental grego, que o termo logos deixa de significar apenas "palavra" assumindo valor de racionalidade demonstrativa e passa assim a opor-se a $m \tilde{y}$ thos no que este termo implica certa magia da palavra que confere aos diferentes gêneros de declamação - poesia, tragédia, retórica, sofistica - um mesmo tipo de eficácia. Enquanto o mỹthos opera no nível da mimese e da participação emocional, o logos instaura um procedimento de pesquisa e exposição que apela somente para a inteligência crítica. Assim, segundo J.P. Vernant (22,p.200), e m seu minucioso exame desta instauração, "tudo o que dá à palavra seu poder de impacto, sua ef icácia sobre o próximo, se encontra então rebaixado ao nível do mỹthos, do fabuloso, do maravilhoso, como se o discurso não pudesse ganhar na ordem do verdadeiro e do inteligivel senão perdendo no mesmo golpe na ordem do agradável, do emocionante e do dramático', .

O mito serve de início para a transmissão de uma sabedoria e sua linguagem narrativa é substituida paulatinamente pela linguagem argumentativa própria do discurso científico, que já não visa à sabedoria mas ao conhecimento (23,p.30-4;12, p.90-1,100). A ascensão histórica do discurso argumentativo tem portanto como contrapartida o desprestígio da seqüência narrativa nas diversas esferas (filosofia, teologia etc.). $\dot{A}$ ciência - assim como era função do mito, e ainda o é em algumas culturas - cabe então explicar os fenômenos que ultrapassam a dimensão do cotidiano, tarefa que ela desempenha com os recursos argumentativos do comentário, da explicação ou da análise. Com a dissociação progressiva dos assuntos importantes e do estilo narrativo, como 
FIKER, R. - Do mito original ao mito ideológico: alguns percursos. Trans/Form/Ação, São Paulo, 7:9-19, 1984.

nota Weinrich no estudo acima mencionado, o princípio mesmo da ciência nos obriga a falar do mito numa liguagem argumentativa.

A desarticulação do elemento narrativo, bem como a dissolução das coordenadas do universo mental que origina e nutre o discurso da "sabedoria" (que é elíptico, metafórico e narrativo, em oposição ao aspecto direto, lógico e argumentativo da postura do "conhecimento") se evidenciam historicamente através de diversas manifestações. Um exemplo é a ressurreição caricata do discurso da sabedoria no universo do conhecimento. Este fenômeno é responsável pela produção de textos que podem ser lidos como paródias involuntárias do estilo iniciático com suas marcas características: receitas de ascese fornecidas em linguagem alegórica, ausência programada de definições diretas e inexistência de textos de autoria do mestre (Cristo e Buda, por exemplo, e Sócrates num certo sentido), sendo porta-voz um discípulo etc.

FIKER, R. - From the Original to the Ideological Myth: some routes. Trans/Form/Acão, São Paulo, 7: $9-19,1984$.

ABSTRACT: This article belongs, as a part of it, originally to the dissertation for the attainment of the Master (M.A.), titled "Myth and Parody : their structure and role in the litterary text", presenled in november 1983, at the Instituto de Estudos da Linguagem/UNICAMP. The present text belongs (1) a chapter that develops the myth conceptualization. It tries to dinamically apprehend some of its basic aspects, in the transition from its original form, such as it occurs in the primitive and archaic societies, to its ideological succedaneous in the context of historic societies.

KEY-WORDS: Myth; mythology; mythic consciousness; ideology; sacred and profane; narrative.

\section{REFERENCIAS BIBLIOGRÁFICAS}

I. BARTHES, R. - Mythologies. Paris, Seuil, 1957.

2. BARTHES, R. - Mudar o próprio objeto. In: - Atualidade do Mito. São Paulo, Duas Cidades, 1977. p.11-14.

3. CAMPBELL, J. - Myths to live by. New York, Bantam, 1972.

4. CAMPBELL, J. - The Masks of God: occidental mythology. Londres, Penguin, 1976.

5. CAMPBELL, J. - The Masks of God: primitive mythology. Londres, Penguin, 1976.

6. ELIADE, M. - Myths, dreams \& mysteries. Londres, Collins, 1976.

7. ELIADE, M. - O Sagrado e o profano. Lisboa, LBL, s/d.

8. ELIADE, M. - Mito e realidade. São Paulo, Perspectiva, 1972.

9. ELIADE, M. - Patterns in comparative religion. New York, Meridiam, 1963.

10. FUNK \& Wagnalls Standard Dictionary of Folklore, Mythology and Legend. New York, 1972.
11. HAUSER, A. - História social de la literatura y el arte. Madrid, Guadarrama, 1969.

12. JOLLES, A. - Formas simples. Sào Paulo, Cultrix, 1976.

13. KERÉNYI, K. - Dal mito genuino al mito tecnicizzato. In: - Attidel colloquio internazionale su Tecnica e casistica. Roma, 1964.

14. KIRK, G. S. - Myth, its meaning \& functions in ancient \& other culture. Londres, Cambridge Univ. Press, 1978.

15. LÉVI-STRAUSS, C. - Antropologia estrutural. Rio de Janeiro, Tempo Brasileiro, 1967.

16. LÉvi-Strauss, C. - O Pensamento selvagem. São Paulo, Nacional, 1970.

17. LÉVI-STRAUSS, C. - Totemismo hoje. Rio de Janeiro, Vozes, 1975.

18. LÉVI-STRAUSS, C. - Le Cruetlecuit. Paris, Plon, 1964.

19. RUTHVEN, K. K. - Myth. Londres, Methuen, 1976.

20. SCHAERER, R. - L'Homme antique. Paris, Payot, 1958. 
FIKER, R. - Do mito original ao mito ideológico: alguns percursos. Trans/Form/Ação, São Paulo, 7:9-19, 1984.

21. VERNANT, J. P. - Les Origines de la pensée grecque. Paris, PUF, 1975.

22. VERNANT, J. P. - Mythe el société en Grèce ancienne. Paris, Maspero, 1974.
23. WEINRICH, H. - Structures narratives du mythe. Poétiquen. ${ }^{\circ} 1,1969$.

24. WELLEK, R. - Concepts of criticism. New Haven, Yale Univ. Press, 1963. 